\title{
Effects of Concept Mapping Modes on Secondary School Students Retention Level in Mathematics in Niger State, Nigeria
}

\author{
Dr. Dantani Ibrahim Wushishi ${ }^{1}$, Kure Isah Danjuma ${ }^{2}$, Hassan Usman ${ }^{3}$ \\ ${ }^{I}$ Department of Science Education Federal University of Technology, Minna, Nigeria. \\ ${ }^{2}$ School of Preliminary Studies, Department of Mathematics Ibrahim BadamasiBabangida University, Lapai, \\ Nigeria \\ ${ }^{3}$ Department of Mathematics Niger State College of Education, Minna, Nigeria.
}

\begin{abstract}
This study investigated the effects of two modes of concept mapping instructional strategies on secondary school students' retention level in mathematics in Niger State. A pretest-posttest randomized group design was adopted. Two research questions were raised and two null hypotheses were formulated and tested at 0.05 significant level. Two hundred and four senior secondary school year one (SSS I) students in six randomly selected co-educational secondary schools in Niger State formed the subjects. The spider mode of concept mapping instructional strategy was used as treatment for control group while the hierarchy mode of concept mapping instructional strategy was used as treatment for experimental group. The instrument for data collection was Algebra retention test on spider and hierarchy modes of concept mapping (ARTSAHCON), an objective type achievement test with reliability co-efficient of 0.76. One way analysis of variance (ANOVA) was used to test the hypothesis. The two hypotheses were not rejected. The results obtained showed that there was no significant difference in the retention level of experimental group and control group, and both spider and hierarchy modes of concept mapping instructional strategies are not gender bias at retention level. It was suggested that spider and hierarchy modes of concept mapping instructional strategies could be used by mathematics teachers for teaching in order to increase students' retention level in mathematics.
\end{abstract}

Keywords: Concept mapping, Students, Retention, Spider mode, Hierarchy mode

\section{Background to the study}

Retention plays a major role in the understanding, comprehensibility and application of mathematical concepts. Akinsola and Popoola (2004) observed that students' performance in mathematics becomes poorer as the test items moved from those requiring ability to recall to those involving some understanding and problem solving. Retention involves the ability to time that an instruction had been given. It is the ability of a learner to demonstrate his/her cognitive skill in the subject. The process of retention has been described by the Macmillan school dictionary (2004) as the ability to remember ideas and facts. Alice (2007) wrote that retention can be measured through verbal recall of learnt materials. Retention of concepts learnt assist in reflective thinking and the retained concepts could be used (Ochonnoger,1997) as quoted by (|Alice, 2007). A number of studies have indicated that teaching methodology can improve learner's retention level.So, Abdullahi (2003) pointed out that using concrete object in learning leads to better retention of information and development of favourable attitude toward science and technology.

In a similar effort, Ezenwa (2005) observed that concept mapping instructional strategy promote knowledge construction, encourage independent thinking and actively foster deeper understanding of concepts or large thinking skills and lead to greater command and ownership of content. Concept mapping is an easy way to encourage very high levels of cognitive performance, when the process is done well. This is one reason concept mapping can also be a very powerful evaluation tool (Edmondson, 2000). Eze (2008), found that students exposed to the concept mapping heuristics achieved and retained concept in trigonometric content better than the students who were taught with conventional method. Awofolaju (2006) and Aiyede (2008) applied concept mapping instructional strategy in teaching mathematics in secondary schools. They found that the strategy was effective in favour of the experimental group that were exposed to concept mapping instructional strategy. Wushishi (2001) asserted that concept mapping is an effective tool in improving secondary school students' achievement in chemistry. Ezenwa (2005) opined that concept mapping is an effective tool in teaching and learning in schools especially for students who are becoming increasingly unable to cope with the study of science.

Akubuilo (2004) reported that any instructional model, which elicits adequate student participation, has profound effects on students' retention.Therefore, the study determined the effects of two modes of concept mapping instructional strategies on secondary school students' retention level in mathematics in Niger State, Nigeria. 


\section{Statement of the Problem}

It has been observed that traditional teaching method is not able to sustain the development of children in mathematics, especially in secondary school education (Agwagah, 2004). So despite the crucial role mathematics play in technology, the performance of students in mathematics at the secondary school level in Nigeria is still below average. The neglect of students centered learning and students view have been identified as a major reason for the problems in secondary school science education (Ezenwa, 2005). .This is made obvious in the West Africa Examination Councils(W.A.E.C) result analysis in mathematics of some selected secondary schools in Nigeria. The result analysis shows, those that scored credit (A1 - C6) in mathematics are less than 40\%. (Quarterly journal of the consumer protection council, 2011).Also the federal government declared, that decline in teacher's quality, as well as quality of instruction and instructional methods are responsible for students' failure (Daily Trust, 2011). The study therefore evaluated the comparative effects spider and hierarchy modes of concept mapping instructional strategies on the retention level of secondary school students in mathematics in three Educational Zones of Niger State, Nigeria. The study also examined the effect of gender on the retention level of students in mathematics.

\section{Objectives of the Study}

The following were the research objectives for the study:

1. To determine the difference in the retention level of students taught Mathematics using spider mode of concept mapping and those taught with hierarchy mode of concept mapping instructional strategy.

2. To determine if gender influences student's retention when both the spider and hierarchy modes of concept mapping are used as instructional strategies.

\section{Research Questions}

1. Is there any difference in the retention level of students taught Mathematics using spider concept mapping and those taught with hierarchy concept mapping?

2. Is there any difference between male and female students retention level among those taught with spider concept mapping and those taught with hierarchy concept mapping?

\section{Null Hypotheses}

The following hypotheses were tested at 0.05 significant level.

$\mathrm{H}_{\mathrm{O}} 1$ : There is no significant difference in the retention level of Senior Secondary School one(SSS I) students taught mathematics using spider mode of concept mapping and those taught with hierarchy mode of concept mapping instructional strategy.

$\mathrm{H}_{\mathrm{O}}$ 2: There is no significance difference in the retention level of male and female SSS I students taught mathematics using spider mode of concept and those taught using hierarchy mode of concept mapping instructional strategy.

\section{Methodology}

The study applied a pretest-posttest randomizedgroup design as recommended by (Jack and Norman, 2000). Two groups of students were used comprising of both male and female students. The control group were taught using spider mode of concept mapping instructional strategy while the experimental group were taught using hierarchy mode of concept mapping instructional strategy. The targeted population for this study is SSSI students of the three educational zone of Niger State with a total population of thirty six thousand five hundred and thirty seven $(36,537)$ students. It is from this population that Two hundred and four SSS I students were randomly selected for the study. One hundred and twenty five(125) of them are male while seventy nine (79) were females.

Algebra retention test on spider and hierarchy mode of concept mapping (ARISAHCON) developed by the researcher was the instrument use in collecting data for the study. The ARISAHCON was validated by team of experts two each from Departments of Science Education and Mathematics and Computer Science of Federal University of Technology, Minna. The reliability co-efficient of 0.76 was obtained for the instrument by using Kunder Richardson formular $\left(\mathrm{KR}_{12}\right)$ method of estimating the reliability of an instrument.Analysis of data collected was done using one way analysis of variance (ANOVA). The analysis of variance is one of the most powerful and widely used procedures as well as a more desirable and efficient technique. It is for large sample sizes and it is a robust technique (Jack and Norman, 2002) 


\section{Results}

$\mathrm{H}_{\mathrm{O} 1}$ : There is no significance difference in the retention level of SSS I students taught mathematics using spider mode of concept mapping and those taught with hierarchy mode of concept mapping instructional strategy.

Table1:ANOVA comparison of the post-posttest mean scores of the experimental and control groups.

\begin{tabular}{llcccc}
\hline Source of Variation & Sum Of Squares & df & Means Square & F cal & Sig. level \\
\hline Between Groups & $6,284.121$ & 31 & 202.714 & 1.270 & $.204^{\text {ns }}$ \\
Within Groups & $11,011.107$ & 69 & 159.581 & & \\
& & & & & \\
Total & $\mathbf{1 7 , 2 9 5 . 2 2 8}$ & $\mathbf{1 0 0}$ & & & \\
\hline
\end{tabular}

\section{ns- notSignificant at 0.05 level}

In table 1 , the observed significant level $\mathrm{P}=0.204$ is greater than $\alpha=0.05$. Hypothesis one (Ho1) is therefore not rejected. There is no significant difference in the retention level between the experiment and control groups. Hence, the level of retention of students taught mathematics using the spider mode of concept mapping instructional strategy is similar to the level of retention of students taught using the hierarchy mode of concept mapping instructional strategy.

$\mathrm{H}_{\mathrm{O} 2}$ : There is no significance difference in the retention level of male and female SSS I students taught mathematics using spider mode of concept mapping and those taught with hierarchy mode of concept mapping instructional strategy.

Table 2: ANOVA comparison of the post-posttest mean scores of male and female experimental group, and male and female control group.

\begin{tabular}{llllll}
\hline Source of Variation & Sum of Squares & df & Mean Square & Fcal & Sig. level \\
\hline Between Groups & 283.742 & 3 & 94.581 & .604 & $.613^{\text {ns }}$ \\
Within Groups & $31,308.547$ & 200 & 156.543 & & \\
Total & $\mathbf{3 1 , 5 9 2 . 2 8 7}$ & $\mathbf{2 0 3}$ & & & \\
\hline
\end{tabular}

\section{ns-significant at 0.05 level}

In table $2, \mathrm{P}=0.613$ is greater than $\alpha=0.05$. This means hypothesis two is not rejected. There is no significant difference in the retention levels of male and female students, taught using spider mode of concept mapping instructional strategy, and those taught using hierarchy mode of concept mapping instructional strategy.

\section{Summary of findings}

The findings of this study are as follows:

1. There is no significant difference in the retention level of students taught mathematics using spider mode of concept mapping and those taught with hierarchy mode of concept mapping instructional strategy.

2. There is no significance difference in the retention level of male and female students taught mathematics using spider mode of concept and those taught using hierarchy mode of concept mapping instructional strategy.

\section{Discussionof results}

The anova result in table 1 shows that there is no statistical significant difference $(\mathrm{F}=1.270, \mathrm{P}>0.05)$ in the retention level of secondary school students taught mathematics using spider mode of concept mapping and those taught using hierarchy mode of concept mapping instructional strategy. That is, there was no significant difference in the post-posttest achievement mean scores of the experimental and control groups. This shows that both the spider and hierarchy modes of concept mapping instruction strategies used enabled the students to retained knowledge of mathematics concept they have been taught equally. Research findings of Eze (2008) on the effect of concept mapping on student's achievement and retention in mathematics are in support of the findings of this study.Eze (2008) found that students exposed to the concept mapping heuristics achieved and retained concept in trigonometric content better than the students who were taught with conventional teaching method.

The anova result in table 2 indicated that there is no significant difference $(F=0.604, P>0.05)$ in the retention level of male and female students taught mathematics concepts using both spider and hierarchy modes of concept mapping instructional strategies. This result showed that both male and female students taught with the two methods of concept mapping instructional strategy demonstrated equal levels of retention in mathematics concept been taught. This means that the retention levels of students taught with concept mapping instructional strategies when learning mathematics is not significantly different by gender. This finding is in 
agreement with the finding of Ezenwa (1993), Manshinkafa (2010). Ezenwa (1993) found that there is no significant difference between male and female students in their retention abilities when taught chemistry concept using concept mapping and guided discovery teaching strategies. Manshinkafa (2010) asserted that the retention levels of the male and female students taught with metacognitive teaching strategies when learning physics is not significantly affected by gender.

\section{Conclusions} strategies:

From the findings of this study, it was concluded that the use of concept mapping instructional

1. Increased the retention ability of mathematics students.

2. Enhance gender equality in performance and retention of the mathematical concept by students.

3. Both the spider and hierarchy modes of concept mapping instructional strategies enhanced the retention level equally.

\section{Recommendations}

Based on the findings of the study the following recommendations were made:

1. Mathematics teachers should incorporate these techniques in teaching mathematics in class rooms in the secondary school.

2. Concept mapping instructional strategy shouldbe included in mathematics pedagogy of teacher training institutions to ensure that the teachers are adequately train on how to use the method.

[1]. Abdullahi, M.H. (2003). Factor affecting the use of instructional material in technical school in Niger state. An Unpublished M.Tech thesis of federal university of technology, Minna.

[2]. Aiyede, S.A. (2008). The effect of concept mapping instructional strategy on mathematics achievement of junior secondary school children.An Unpublished M.Ed thesis department of education, Ahmadu Bello university, Zaria.

[3]. Akinsola, M. K, and Popoola, A.A, (2004).A comparative study of the effectiveness of two strategies of solving mathematics problems on the academic achievement of secondary school students. The journal of the mathematical association of Nigeria, volume 29 number 1, September, 2004.

[4]. Akubuilo, D.U. (2004). The effects of problem solving instructional strategies on students' achievement and retention in biology with respect to location in Enugu State.Journal of the science teachers association of Nigeria 39 (122), 93 - 99.

[5]. Alice, D. J. (2007).The use of analogy to enhance performance and retention of concepts in evolution among NCE III biology students in Niger State.An Unpublished M.Sc (ED) thesis, Ahmadu Bello University, Zaria, Nigeria.

[6]. Awofobaju, M.A (2006). The effect of concept mapping instructional strategy on Junior Secondary School Students' achievement in Algebra in Minna Metropolis, Niger State.An Unpublished M.Tech thesis, Federal University of technology, Minna.

[7]. Edmondson, K. (2000). Assessing science understanding through concept maps.In Mintzeb, J, J. Wandersee\& J. Novak (EDS), Assessing science understanding (PP. $19-40$ ).san Diego; Academic press.

[8]. Eze, J.E. (2008) effects of concept mapping heuristic on students achievement and retention in mathematics. ABACUS Journal of mathematics association of Nigeria. 33, $80-085$.

[9]. Ezenwa, V.I (1993). Concept mapping Metacognitive instructional strategy within the constructive framework for raising the standard of performance of students in science savanna 14(2), $114-125$.

[10]. Ezenwa, V. I. (2005). Concept mapping: a veritable tool in science education. Inaugural lecture series of Federal university of technology, Minna.

[11]. Jark R.F and Norman, E.W (2000).How to design and evaluate research in education.Forth edition, mograw-hill higher education

[12]. Maishikafa, G. (2010). Effects of metacognitive teaching strategies on academic performance, school low achievers in physics. An unpublished M.Tech thesis, department of science education, federal university of Technology, Minna.

[13]. Wushishi, D. I. (2001). Effects of concept mapping and teaching with analogy on secondary school students achievement in chemistry. An unpublished M.Ed dissertation, faculty of education and extension services, UsmanDanfodioyo University, Sokoto, Nigeria. 